FRI0201

HEALTHY INDIVIDUALS AT INCREASED RISK FOR AXIAL SPONDYLOARTHRITIS WOULD CONSIDER USING MEDICATION IN A PREVENTIVE SETTING

J.J. de Winter ${ }^{1}$, H.M. De Jong ${ }^{1}$, P.T. Nieuwkerk ${ }^{2}$, I.E. van der Horst-Bruinsma ${ }^{3}$, D. L. Baeten ${ }^{1}$, M.G. van de Sande ${ }^{1} .{ }^{1}$ Clinical immunology and rheumatology; ${ }^{2}$ Medical Psychology, Academic Medical Center, ${ }^{3}$ Rheumatology, VU medical center, Amsterdam, Netherlands

Background: Axial spondyloarthritis $(\mathrm{axSpA})$ is a chronic inflammatory disease with a diagnostic delay of 5-10 years. Treating the disease in the pre-clinica phase before the disease becomes clinically manifest is not yet clinical practice, although initiatives to diagnose axSpA in an early phase such as the SPondyloArthritis Caught Early (SPACE) cohort and the pre-SpA cohort might enable early or even pre-clinical detection and thus treatment of SpA. Possibly, very early treatment might be able to stop the disease process hereby preventing the development of irreversible structural damage or, ideally, even disease onset.

Objectives: To study the willingness of individuals with an increased risk for $\mathrm{SpA}$ to use medication in a preventive setting.

Methods: Healthy first degree relatives of HLA-B27 positive axSpA patients from the Pre-SpA cohort completed a questionnaire consisting of different hypothetical scenarios varying in 1) the risk of developing axSpA, 2) the occurrence and nature of possible side effects, and 3 ) the effectiveness of the medication. Moreover, the survey included multiple choice questions about participants' perception towards SpA and preventive medication.

Results: The response rate was $81.5 \%$ (106 out of 130). Figure 1 shows the comparison of the different scenarios. The percentage of individuals willing to use preventive medication causing no side effects varied between $63.2 \%$ (with $30 \% \mathrm{SpA}$ risk) and $91.5 \%$ (with $70 \% \mathrm{SpA}$ risk). The percentage of individuals willing to use this medication varied between $27.4 \%$ (with $30 \%$ SpA risk) and $51.9 \%$ (with $70 \%$ $\mathrm{SpA}$ risk) if the preventive medication would possibly cause infections. This percentage was $32.1 \%$ (with $30 \%$ SpA risk) if the medication would possibly cause mild side effects. The percentage of individuals willing to use preventive medication that would cause a delay in onset of SpA of 10 years (with $70 \% \mathrm{SpA}$ risk) was $72 \%$. The willingness of individuals to use preventive medication was negatively influenced by their own risk assessment of developing $S p A(B=0.16, p=0.001)$ and was not primarily influenced by costs $(0.9 \%)$ or the route of administration $(0 \%)$

Conclusions: 1. Individuals at increased risk for SpA would consider using preventive medication.

2. Their willingness to use preventive medication is largely influenced by the formal likelihood to develop SpA, by their own perception of the disease and by the likelihood of side effects.

3. Their willingness to use preventive medication is not primarily influenced by costs and the route of administration.

Disclosure of Interest: None declared

DOI: 10.1136/annrheumdis-2018-eular.5182

\section{FRI0202 INERTIAL MOTION SENSORS USING THE VIMOVEC SYSTEM IS A VALID METHOD TO ASSESS SPINAL MOBILITY IN PATIENTS WITH AXIAL SPONDYLOARTHRITIS}

I.C. Aranda-Valera ${ }^{1}$, J.L. Garrido-Castro ${ }^{2}$, I. Martinez-Sanchez ${ }^{2}$, C. Gonzalez ${ }^{2}$ P. Gardiner ${ }^{3}$, P.M. Machado ${ }^{4}$, E. Collantes ${ }^{1}$, on behalf of iMaxSpA Study Group. ${ }^{1} \mathrm{HU}$ Reina Sofia; ${ }^{2} I M I B I C$, Cordoba, Spain; ${ }^{3}$ WHSCT, Londonderry; ${ }^{4}$ UCL, London, UK

Background: Spinal mobility measures are recommended for the assessment axial spondyloarthritis (axSpA). Simple, low-tech tools as goniometers and metric tapes are commonly used, resulting in high variability and low accuracy of the measurements. More recently, advanced technological systems have facilitated the measurement of human mobility with high precision, such as motion capture systems like the UCOTrack and its index, the UCOASMI, validated for use in axSpA patients. The development on inertial measurement units (IMUs) has produce wearable, cheap and self-contained devices that can measure motion usually using triads of gyroscopes, accelerometers and magnetometers. Some of the mobility angles measured using motion capture systems can also be measured using IMUs placed in pre-defined anatomical locations.

Objectives: To evaluate the validity of IMUs using the ViMove@ system for measuring spinal mobility in patients with axSpA.

Methods: We recruited 20 patients with axSpA from the HU Reina Sofia of Cordoba. The UCOTrack was used as the gold-standard system to obtain mobility measurements. UCOTrack measurements were compared with ViMove@ measurements, a system that includes two IMU sensors located in the lumbar spine (pelvis and L1- figure 1) or in the neck (occiput and T3). Conventional metrology measures and patient-reported outcomes were also collected.

Results: The table presents the measurements obtained at the L1 and occiput levels. UCOTrack and ViMove@ measurements were very similar, with Root
Mean Square Errors (RMSE) less than $10^{\circ}$ and Variation Coefficients (VC) less than $10 \%$. We found high intraclass correlation coefficients (ICC) between the two systems (0.84-0.99). Measurements with both systems correlated strongly and significantly with BASMI (0.60-0.92) and BASFI (0.51-0.84), but not with BASDAI.

\begin{tabular}{|c|c|c|c|c|c|}
\hline $\begin{array}{l}\text { Type of } \\
\text { measurement }\end{array}$ & UCOTrack@ & ViMove@ & vC & RMSE & ICC \\
\hline \multicolumn{6}{|l|}{ Lumbar (L1) } \\
\hline Anterio flexion & $103.6(17.3)$ & $\begin{array}{c}99.0 \\
(17.4)\end{array}$ & $4.4 \%$ & 6.57 & 0.93 \\
\hline Extension & $24.6(9.3)$ & $22.3(9.6)$ & $9.4 \%$ & 4.22 & 0.90 \\
\hline Left rotation & 27.7 (10.4) & $\begin{array}{l}27.4 \\
(11.0)\end{array}$ & $1.1 \%$ & 1.83 & 0.99 \\
\hline Right rotation & $26.8(10.4)$ & $\begin{array}{l}25.3 \\
(10.1)\end{array}$ & $5.6 \%$ & 3.14 & 0.95 \\
\hline Left lateral flexion & 70.7 (13.9) & $\begin{array}{c}72.6 \\
(16.6)\end{array}$ & $2.7 \%$ & 8.71 & 0.84 \\
\hline Right lateral flexion & $68.4(15.4)$ & $\begin{array}{l}67.6 \\
(16.7)\end{array}$ & $1.2 \%$ & 7.87 & 0.88 \\
\hline \multicolumn{6}{|l|}{ Cervical (occiput) } \\
\hline Flexion & $50.9(12.5)$ & $\begin{array}{c}52.3 \\
(12.8)\end{array}$ & $2.8 \%$ & 2.73 & 0.98 \\
\hline Extension & $43.1(16.0)$ & $\begin{array}{c}39.3 \\
(14.4)\end{array}$ & $8.8 \%$ & 5.44 & 0.94 \\
\hline Left rotation & $66.1(20.2)$ & $\begin{array}{l}63.8 \\
(20.5)\end{array}$ & $3.5 \%$ & 9.13 & 0.90 \\
\hline Right rotation & $62.1(19.2)$ & $\begin{array}{l}64.7 \\
(21.7)\end{array}$ & $4.2 \%$ & 9.72 & 0.89 \\
\hline Left lateral flexion & $34.3(15.8)$ & $\begin{array}{c}32.9 \\
(15.5)\end{array}$ & $4.1 \%$ & 7.77 & 0.88 \\
\hline Right lateral flexion & 34.7 (15.9) & $\begin{array}{c}34.0 \\
(16.3)\end{array}$ & $2.0 \%$ & 7.10 & 0.90 \\
\hline
\end{tabular}

All measures are expressed in degrees.

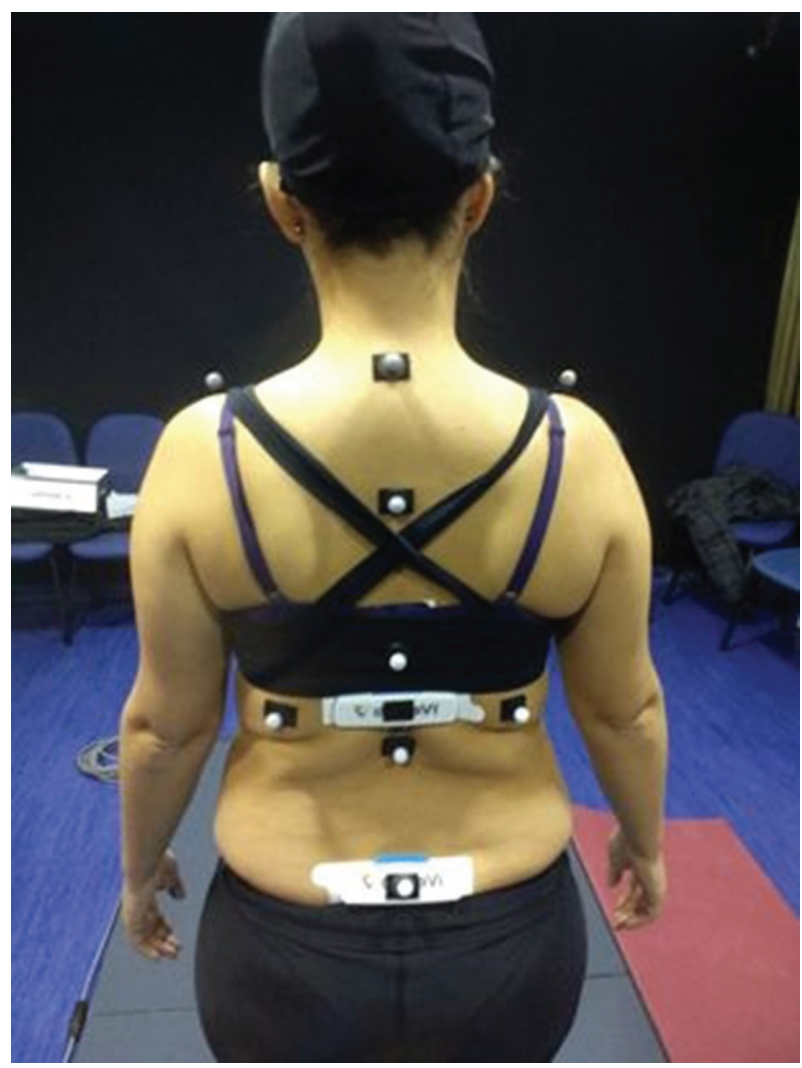

Conclusions: The ViMove $\odot$, an IMU based system, is a valid method to assess spinal mobility in patients with axSpA. There was excellent agreement between ViMove $\odot$ and UCOTrack and a strong correlations with conventional metrology (BASMI) and patient-reported physical function (BASFI). IMU systems are more feasible than motion capture systems because they do not require a motion laboratory and results can be obtained more quickly in an objective and quantitative way. The ViMove( system has potential for use both in the clinical and research setting and further evaluation of its reproducibility and sensitivity to change should be undertaken.

Acknowledgements: This study has been funded by Foreum (Foundation for Research in Rheumatology) 
Disclosure of Interest: None declared

DOI: 10.1136/annrheumdis-2018-eular.1688

\section{FRI0203 THE LINK BETWEEN COPD AND ANKYLOSING SPONDYLITIS: A POPULATION BASED STUDY}

K. Sharif ${ }^{1}$, A. Watad ${ }^{2}$, S. Tiosano ${ }^{2}$, Y. Yavne ${ }^{2}$, D. Comanehster ${ }^{3}$, A. Cohen ${ }^{4}$ H. Amital ${ }^{2}$. ${ }^{1}$ Sheba medical centre, Tel aviv, ${ }^{2}$ Sheba Medical Centre; ${ }^{3}$ Clalit, ${ }^{4} \mathrm{CLalit}$ health services, Ramat Gan, Israel

Background: Ankylosing spondylitis (AS) is one of the most common and severe subtypes of the spondyloarthropathies. Extra-articular involvement among AS patients, including lung disease, has been described widely. Chronic obstructive pulmonary disease (COPD) has been linked to several autoimmune diseases, however, very few studies have investigated the association between AS and COPD.

Objectives: To assess whether an association exists between AS and COPD.

Methods: A population-based cross-sectional study was conducted using data retrieved from the largest electronic medical records database in Israel, the Clalit Health Services (CHS). Patients were defined as having AS or COPD when there was at least one such documented diagnosis in their medical records. The proportion of COPD was compared between AS patients and controls. A logistic regression model was used to estimate the association between AS and COPD in a multivariate analysis adjusted for age, gender and smoking status

Results: The study included 4076 patients with AS and 20290 age- and sex-frequency matched controls. The proportion of COPD in AS patients was higher than in controls ( $46 \%$ vs. $18 \%$, respectively, $\mathrm{p}<0.001)$. Multivariate logistic regression demonstrated a robust independent association between AS and COPD (OR 1.225, $\mathrm{p}=0.031$ ).

Abstract FRI0203 - Table 1. Interactions between COPD, covariates by strata and AS

\begin{tabular}{|c|c|c|c|c|c|}
\hline & $\begin{array}{c}\text { ALL } \\
\mathbf{n}=24366\end{array}$ & $\begin{array}{l}\text { Controls } \\
n=20290\end{array}$ & AS $n=4076$ & OR & $\mathbf{P}$ \\
\hline COPD & $628(2.58 \%)$ & 431 (2.12\%) & $\begin{array}{c}197 \\
(4.83 \%)\end{array}$ & $\begin{array}{c}2.34 \\
{[1.97 ; 2.78]}\end{array}$ & $<0.001$ \\
\hline $\begin{array}{l}\text { Gender: } \\
\text { Female }\end{array}$ & 172 (1.95\%) & $117(1.60 \%)$ & 55 (3.74\%) & $\begin{array}{c}2.40 \\
{[1.72 ; 3.30]}\end{array}$ & $<0.001$ \\
\hline Gender: Male & $456(2.93 \%)$ & $314(2.42 \%)$ & $\begin{array}{c}142 \\
(5.45 \%)\end{array}$ & $\begin{array}{c}2.32 \\
{[1.89 ; 2.84]}\end{array}$ & $<0.001$ \\
\hline Age: $18-44$ & $14(0.19 \%)$ & $8(0.13 \%)$ & $6(0.50 \%)$ & $\begin{array}{c}3.94 \\
{[1.27 ; 11.6]}\end{array}$ & 0.020 \\
\hline Age: 45-69 & 306 (2.42\%) & $189(1.78 \%)$ & $\begin{array}{c}117 \\
(5.70 \%)\end{array}$ & $\begin{array}{c}3.34 \\
{[2.63 ; 4.22]}\end{array}$ & $<0.001$ \\
\hline Age: $70_{+}$ & 308 (7.25\%) & $234(6.83 \%)$ & $74(9.01 \%)$ & $\begin{array}{c}1.35 \\
{[1.02 ; 1.77]}\end{array}$ & 0.034 \\
\hline SES: Low & 268 (5.35\%) & 193 (5.47\%) & 75 (5.04\%) & $\begin{array}{c}0.92 \\
{[0.69 ; 1.20]}\end{array}$ & 0.542 \\
\hline SES: Medium & $247(4.72 \%)$ & $154(4.36 \%)$ & 93 (5.47\%) & $\begin{array}{c}1.27 \\
{[0.97 ; 1.65]}\end{array}$ & 0.077 \\
\hline SES: High & 97 (3.46\%) & 68 (3.54\%) & $29(3.27 \%)$ & $\begin{array}{c}0.93 \\
{[0.59 ; 1.43]}\end{array}$ & 0.729 \\
\hline $\mathrm{BMI} \leq 25$ & $172(4.11 \%)$ & $111(3.86 \%)$ & 61 (4.64\%) & $\begin{array}{c}1.21 \\
{[0.88 ; 1.66]}\end{array}$ & 0.242 \\
\hline $\mathrm{BMI}>25$ & $338(4.49 \%)$ & $204(4.20 \%)$ & $\begin{array}{c}134 \\
(5.04 \%)\end{array}$ & $\begin{array}{c}1.21 \\
{[0.97 ; 1.51]}\end{array}$ & 0.094 \\
\hline Smoking & $454(8.23 \%)$ & 304 (8.34\%) & $\begin{array}{c}150 \\
(8.01 \%)\end{array}$ & $\begin{array}{c}0.96 \\
{[0.78 ; 1.17]}\end{array}$ & 0.674 \\
\hline
\end{tabular}

$\mathrm{N}$ : number of cases; AS: ankylosing spondylitis; BMI: body mass index $\left(\mathrm{kg} / \mathrm{m}^{2}\right)$; SES: socioeconomic class; COPD: chronic obstructive pulmonary disease.

Note: The table presents stratified analysis of COPD patients. Reference category for each stratum is patients without COPD.

Abstract FRI0203 - Table 2. Logistic regression - Covariates associated with COPD

\begin{tabular}{lccc}
\hline Variable & OR & $\mathbf{C l}$ & $\mathbf{p}$ \\
\hline Age (years) & 1.078 & 1.0711 .085 & $<0.001$ \\
Gender: & 1.042 & 0.8631 .263 & .671 \\
Male & & & \\
Smoking & 9.862 & 8.174 & $<0.001$ \\
AS & 1.225 & 11.949 & .031 \\
\hline
\end{tabular}

OR: odds ratio; $\mathrm{Cl}$ : confidence interval; AS: ankylosing spondylitis; COPD: chronic obstructive pulmonary disease.

Conclusions: Our study supports an association between AS and COPD, further extending the link between COPD and autoimmune diseases. This finding highlights the importance of smoking cessation in AS patients and raises the question of whether COPD screening may be warranted.

Disclosure of Interest: None declared

DOI: 10.1136/annrheumdis-2018-eular.3917

\section{FRI0204 RADIOGRAPHIC PROGRESSION OF} SPONDYLOARTRITIS PATIENTS AFTER 13 YEARS OF FOLLOW UP: DATA FROM THE REGISPONSER DATABASE

L. Pérez Sánchez ${ }^{1,2,3}$, P. Font ${ }^{1,2,3}$, C. López ${ }^{1,2,3}$, L. Bautista ${ }^{1,2,3}$, L. Ladehesa ${ }^{1,2,3}$ I. Gómez ${ }^{1,2,3}$, A. Escudero ${ }^{1,2,3}$, E. Collantes ${ }^{1,2,3}$, M.C. Castro ${ }^{1,2,3} .{ }^{1}$ Reina Sofia University Hospital; ${ }^{2}$ IMIBIC, ${ }^{3}$ University of Cordoba, Cordoba, Spain

Objectives: To describe the radiographic evolution after 13 years of follow-up in a monographic consultation of patients with Axial Spondyloarthritis (EspAax) included in REGISPONSER at the Reina Sofía University Hospital in Córdoba.

Methods: Seventy eight SpA patients from the REGISPONSER registry were analysed in an observational study, which were evaluated for the first time in the year 2004-2005. The last x-rays analysis of the cervical and lumbar spine, pelvis and hips were recorded. Two independent observers evaluated the radiographs and calculated the BASRI index. The interobserver concordance was studied using Cohen's Kappa statistic. Finally, radiographic progression was assessed using the McNemar test.

Results: Sixty one SpA patients were radiographicaly evaluated at baseline and after 11 (1.7) years of follow-up. A complete radiographic study was recorded in 38 of them. The baseline characteristics, including BASRI values, as well as the treatment received are listed in table 1 . The strength of the interobserver concordance in the radiographic analysis was considerable in hips $(k=0.77, p<0.001)$ and almost perfect at the levels of the cervical spine $(k=0.88, p<0.001)$, lumbar spine $(\mathrm{k}=0.87, \mathrm{p}<0.001)$ and sacroiliac joints $(\mathrm{k}=0.84, \mathrm{p}<0.001)$. The BASRIs and BAS RIt scores were 7.5 (2.9) and 8.8 (4.1) respectively. Moreover, during the follow up, the BASRIt was increased in $1.23(\mathrm{p}=0.014)$. Individual analysis of the different components of BASRI, showed that $42.1 \%$ of SpA patients got worse regarding the score corresponding to the cervical spine $(p<0.001), 28.9 \%$ to the lumbar spine $(p=0.057), 15.8 \%$ to the hip $(p=0.754)$ and no worsening was found in sacroiliac $(p=0.500)$.

Abstract FRI0204 - Table 1. Baseline characteristics and current treatment of the cohort $\mathrm{N}=38$ for the radiographic study.

\begin{tabular}{|c|c|c|c|c|}
\hline $\begin{array}{l}\text { Type of SpA } \\
N(\%)\end{array}$ & $\begin{array}{l}\text { AS } 38 \\
(100 \%)\end{array}$ & $\begin{array}{c}\text { BASRIs } \\
\text { baseline } \\
\text { Mean (DS) } \\
\text { BASRIt } \\
\text { baseline } \\
\text { Mean (DS) }\end{array}$ & $\begin{array}{l}6.44(2.91) \\
7.60(3.96)\end{array}$ & $\begin{array}{c}\text { Current treatment } \\
\text { NSAIDs } \\
\text { N(\%) } \\
\text { Daily treatment: } 22 \\
(57.9 \%) \\
\text { Casual treatment: } 13 \\
(34.2 \%) \\
\text { Response: } 35(92.1 \%) \\
\text { Type: - } 18 \text { COX-2 } \\
\text { selective }(51.4 \%) \\
-7 \text { Diclofenac }(18.4 \%) \\
\text { - } 5 \text { Indomethacin } \\
(13.2 \%) \\
-5 \text { Others }(13.2 \%)\end{array}$ \\
\hline $\begin{array}{l}\text { Time of evolution } \\
\text { Diagnosis-inclusion } \\
\text { in the registry } \\
\text { Mean (DS) years }\end{array}$ & $11(7.1)$ & $\begin{array}{c}\text { Degree of } \\
\text { sacroiliitis } \\
\text { Me (RI) }\end{array}$ & $\begin{array}{c}4 \\
r^{3-4}\end{array}$ & $\begin{array}{c}\text { Current treatment } \\
\mathbf{N}(\%) \text { cDMARDs - } \\
\text { Sulfasalazine } 1(2.7 \%) \\
\text { - Methotrexate } 1(2.7 \%)\end{array}$ \\
\hline $\begin{array}{l}\text { Sex } \\
\text { Male } \\
\text { Female } \\
\mathrm{N}(\%)\end{array}$ & $\begin{array}{c}34 \\
(89.5) \\
4(10.5)\end{array}$ & $\begin{array}{l}\text { Degree of } \\
\text { cervical spine } \\
\mathrm{Me}(\mathrm{RI})\end{array}$ & $\begin{array}{c}1 \\
(0-2)\end{array}$ & $\begin{array}{c}\text { Current treatment } \\
\text { N(\%) bDMARDs } \\
10(26.3 \%)-4 \\
\text { Golimumab }(10.5 \%) \\
\text { - } 3 \text { Etanercept }(7.9 \%) \\
\text { - } 1 \text { Adalimumab }(2.6 \%) \\
-1 \text { Infliximab }(2.6 \%) \\
\text { - } 1 \text { Secukinumab } \\
(2.6 \%)\end{array}$ \\
\hline $\begin{array}{l}\text { Age } \\
\text { Mean (DS) years }\end{array}$ & $\begin{array}{l}58.2 \\
(7.9)\end{array}$ & $\begin{array}{l}\text { Degree of hips } \\
\quad M e(R I)\end{array}$ & $\begin{array}{c}1 \\
(0-2)\end{array}$ & \\
\hline
\end{tabular}

Conclusions: This study provides information related to the structural progression of patients followed in a monographic consultation of SpA after 13 years of follow-up. Radiographic evolution was significantly noticed in relation to the tota score of the BASRI. However, analysing the individual scores it seems that the cervical spine was the segment where there was greater radiographic progres sion. We did not find worsening of BASRI in sacroiliac due to the fact that the most of patients already had an advanced degree of sacroileitis in the first visit of the registry.

Disclosure of Interest: None declared

DOI: 10.1136/annrheumdis-2018-eular.5637 